Article

\title{
Evaluation of the Effectiveness of N-Acetylcysteine (NAC) and $N$-acetylcysteine-cyclodextrins Multi-Composite in Pseudomonas aeruginosa Biofilm Formation
}

\author{
Marta Guerini, Paola Perugini * and Pietro Grisoli \\ Department of Drug Sciences, University of Pavia, Via Taramelli 12, 27100 Pavia, Italy; \\ marta.guerini01@universitadipavia.it (M.G.); pietro.grisoli@unipv.it (P.G.) \\ * Correspondence: paola.perugini@unipv.it
}

Received: 19 March 2020; Accepted: 13 May 2020; Published: 17 May 2020

check for updates

\begin{abstract}
Pseudomonas aeruginosa is a gram-negative bacillus involved in biofilm production in several lung diseases. In this study, the in vitro anti-biofilm effect of both $\mathrm{N}$-acetylcysteine (NAC) - a well-known antioxidant compound and GSH prodrug — and NACESOL ${ }^{\mathrm{TM}}$ - a new multicomposite based on NAC, resveratrol, and cyclodextrins-was investigated by evaluation of reduction of bacterial colonies growth. Physico-chemical analysis of NACESOL ${ }^{\mathrm{TM}}$ was performed by differential scanning calorimetry (DSC), Fourier-transform infrared (FT-IR) spectroscopy, and X-ray powder diffraction (XRPD) techniques. The anti-biofilm activity of NAC and NACESOL ${ }^{\mathrm{TM}}$, expressed as percentage of biofilm reduction, revealed an increased biological activity of multicomposite at low concentrations. Furthermore, the NAC activity against $P$. aeruginosa biofilm was also studied using scanning electron microscopy (SEM) joined to the energy dispersive spectrometry (EDS) technique, which is able to evaluate the reduction of sulfur element on biofilm surface. The use of SEM-EDS highlights the biofilm amount decrease with increasing NAC concentration. This work permitted us to highlight the minimum concentration of NAC able to interact in the P. aeruginosa biofilm formation process and the promising use of a new composite based on NAC and cyclodextrins.
\end{abstract}

Keywords: Pseudomonas aeruginosa; cystic fibrosis; N-acetylcysteine; Scanning Electron Microscopy; multicomposite; activity against biofilm

\section{Introduction}

Pseudomonas aeruginosa is a non-capsulate and non-spore-forming Gram-negative bacillus that most commonly affects the lower respiratory system in humans. This bacillus finds favorable conditions for growth in affected lung, with low oxygen concentrations promoting biofilm development [1,2]. Moreover, it commonly forms biofilm on medical devices, contact lenses, and catheters [3].

When the cells permanently adhere to a substrate, i.e., they are not removed by simple rinsing, they begin to divide and produce extracellular polymeric substances (EPSs) formed mainly by exopolysaccharides, DNA, and proteins [4]. EPS represents the biofilm's matrix, embodying approximately the $80 \%$ of it. The EPS is not homogeneous but contains some "layers" of bacteria and aqueous pores inside it, which allow the passage of oxygen and nutrients [5]. The organisms associated with the biofilm grow much slower than the planktonic cells (due to the lack of nutrients and oxygen) and remain in a more quiescent form.

The most superficial cells break off from the biofilm due to cell division, and in this way, they are able to migrate and form another biofilm in a different district [6]. It is therefore possible that these detached cells create a systemic infection in the patient. Studies have shown that $P$. aeruginosa forms 
clusters of cells within the endobronchial part of the lungs of patients affected by lung diseases [7], and these clusters are analogous to the microcolonies formed by the bacterium itself when it grows in vitro on abiotic surfaces [8]. The biofilm formed by P. aeruginosa is characterized by the presence of at least three specific exopolysaccharides, which represent a defensive barrier against antimicrobial and against the host's immune system [9]: alginate, polysaccharide synthesis locus (Psl) and pellicles (Pel) polysaccharides [10]. Alginates is characterized by linear polyanionic exopolysaccharides composed of uronic acid and contributes to decrease the susceptibility of biofilm to antibiotic treatment and human antibacterial defense mechanisms [11]. Psl is a polysaccharide rich in mannose and galactose, is produced by planktonic cells, and is involved in the attachment of the bacteria on the surface and in the mature biofilm formation [12]. Pel is a cellulose-like polymer, is glucose-rich, and is able to form a pellicle in the air-liquid interface. The presence of Pel is evident in the wrinkle colony phenotype of P. aeruginosa [13].

This work focuses on the action of a new multicomposite, not yet on the market, based on $\mathrm{N}$-acetylcysteine (NAC) within $\alpha$-cyclodextrin against the formation of Pseudomonas aeruginosa biofilm. NAC, a well-known antioxidant glutathione (GSH) prodrug and a disulfide bond disrupter, is able to prevent the attachment of the biofilm from the substrate and thus facilitate the use of antibiotics [14,15]. Zhao et al. demonstrated that there is no interaction between NAC and ciprofloxacin to eradicate biofilm infections, but synergy (50\%) or no interactions (50\%) [16].

This molecule is considered a non-antibiotic drug with anti-bacterial properties, and the mechanism of action is probably due to the sulfhydryl group, which may react with bacterial cell proteins or may act by competitively inhibiting cysteine utilization. Olofosson et al. evaluated the NAC action on a wide range of strains [17], while Zhao $\mathrm{T}$ et al. discovered the minimum inhibitory concentrations (MICs) against $P$. aeruginosa between $10 \mathrm{mg} \cdot \mathrm{mL}^{-1}$ and $40 \mathrm{mg} \cdot \mathrm{mL}^{-1}$ [16].

NACESOL ${ }^{\text {TM }}$ is a new multi-composite (MComp) based on NAC within $\alpha$-cyclodextrin (10:15:75 $\mathrm{w}: \mathrm{w}: \mathrm{w})$ and obtained with a proprietary technology [18]. By means of this technology, a dry grinding of a mixture of an active (NAC), a carrier ( $\alpha$-cyclodextrin), and an auxiliary agent (resveratrol) powder allows the solid components of the system to interact without the aid of solvents and in a very short time, into a multi-composite material where components are held together by means of weak forces. This product presents a twofold purpose: to exert a protective effect on the NAC, easily active and extensively oxidizable [19], and to promote a booster effect on antioxidant activity thanks to the presence of resveratrol [20].

The effectiveness of both NAC and MComp compounds against the biofilm formation process by P. aeruginosa was evaluated by microbial assay. Tests were supported by scanning electron microscopy (SEM) coupled with composition microanalysis by energy dispersive spectrometry.

In SEM, an accelerated beam of mono-energetic electrons is focused on the surface of the sample and is scanned over a small area in a roster pattern. As secondary electrons have a maximum depth of depth of about $100 \mathrm{~A}$, SEM represents a good technique of exclusively probing the surface of the samples at the sub-micron level [21].

\section{Materials}

$\mathrm{N}$-acetylcysteine powder was purchased from Farmalabor (Milan, Italy). NACESOL ${ }^{\mathrm{TM}}$, a multi-composite powder based on $\mathrm{N}$-acetyl-cysteine, alpha-cyclodextrins, and resveratrol, was a gift from Asoltech s.r.l., Trieste, Italy. Tryptone soya Agar (TSA) and tryptone soya broth (TSB) were purchased from Oxoid (Basingstoke, UK). A stainless-steel surface with a diameter of $2.05 \mathrm{~cm}$ was purchased from CMB Engineering Group (Worcester, UK). A Zorbax ODS C18 $4.6 \times 250 \mathrm{~mm} 5 \mu \mathrm{m}$ column was purchased from Agilent (Milan, Italy). Phosphate buffer $\mathrm{pH}=3$ was purchased from WWR INTERNATIONAL PBI (Milan, Italy). Acetonitrile HPLC grade and $\mathrm{OsO}_{4}$ were purchased from Sigma-Aldrich (Milan, Italy). 


\section{Methods}

\subsection{Analytical Quantification of N-Acetylcysteine within $N A C E S O L^{T M}$}

Quantitative analysis of N-Acetylcysteine within NACESOL ${ }^{\mathrm{TM}}$ was performed using a suitably modified HPLC method [22]. Briefly, an instrument model HP1100 was used (Agilent, Milan, Italy) equipped with Zorbax ODS column $(4.6 \times 250 \mathrm{~mm}, 5 \mu \mathrm{m})$, and the UV-detector set at $220 \mathrm{~nm}$. Analyses were carried out at $0.8 \mathrm{~mL} \cdot \mathrm{min}^{-1}$ flow rate. The injection volume was $20 \mu \mathrm{L}$. The mobile phase was $\mathrm{H}_{3} \mathrm{PO}_{4}$ solution $(\mathrm{pH}=3)$ : Acetonitrile $(90: 10 \mathrm{v}: \mathrm{v})$. Retention time for NAC was $4.25 \mathrm{~min}$. The limit of quantification (signal to noise ratio 10:1) was $0.02 \mathrm{mg} \cdot \mathrm{mL}^{-1}$. A calibration curve of NAC solution ranging between 0.8 and $0.02 \mathrm{mg} \cdot \mathrm{mL}^{-1}$ was used.

Standard solutions of analyte were prepared by diluting a stock solution of $10 \mathrm{mg} \cdot \mathrm{mL}^{-1} \mathrm{NAC}$ in acidic medium $(\mathrm{pH}=3$ ) with MilliQ water.

For the quantification of NAC within the NACESOL ${ }^{\mathrm{TM}}$, an appropriate amount was weighed and then suspended in acidic medium $(\mathrm{pH}=3)$ with MilliQ water, filtered with hydrophilic filters, diluted, and analyzed.

\subsection{Chemico-Physical Characterization}

\subsubsection{Thermal Analysis: Differential Scanning Calorimetry (DSC)}

Thermal characterization was carried out using a differential scanning calorimetry (DSC) Q2000 apparatus interfaced with a TA 5000 data station (TA Instruments, New Castle, Germany). The DSC instrument was calibrated using ultrapure indium $\left(99.999 \%\right.$; melting point $=156.6^{\circ} \mathrm{C} ; \Delta \mathrm{H}=28.54 \mathrm{~J} \cdot \mathrm{g}^{-1}$ ) as standard. The calorimetric measurements were carried out in open standard aluminum pans under nitrogen flow $\left(45 \mathrm{~mL} \cdot \mathrm{min}^{-1}\right)$ at 1 and $2 \mathrm{~K} \cdot \mathrm{min}^{-1}$. Sample mass remained proximally $4 \mathrm{mg}$. All data from thermal measurements are the average of three or more experiments. All the temperature values reported for the thermal effects are onset temperatures.

\subsubsection{X-ray Powder Diffraction (XRPD) Measurements}

X-ray powder diffraction (XRPD) patterns were collected by a powder diffractometer D5005 (Bruker, Karlsruhe, Germany) (CuK $\alpha$ radiation, $\lambda(\mathrm{K} \alpha 1)=1.54056 \AA$; voltage of $40 \mathrm{kV}$ and current of $40 \mathrm{~mA}$ ) equipped with a $\theta-\theta$ vertical goniometer, Ni filter, monochromator, and scintillator counter. The patterns were recorded at room temperature in step scan mode (step size: $0.020^{\circ}$, counting time: 3 s per step) in the $2 \theta^{\circ}=3-35^{\circ}$ angular range.

\subsubsection{Fourier-Transform Infrared (FTIR) Spectroscopy Measurements}

Fourier-transform infrared (FTIR) spectra were obtained using a Nicolet FT-IR iS10 Spectrometer (Nicolet, Madison, WI, USA) equipped with attenuated total reflectance sampling accessory (Smart iTR with diamond plate) by coadding 32 scans in the $4000-650 \mathrm{~cm}^{-1}$ range with a resolution set at $4 \mathrm{~cm}^{-1}$.

All measurements were performed on the pure components (NAC, NACESOL ${ }^{\mathrm{TM}}$, resveratrol, cyclodextrin), and on the physical mixture NAC:resveratrol:cyclodextrin (10:15:75 w:w:w).

\subsection{Biofilm Assay}

\subsubsection{Microbial Strains and Culture Conditions}

The strain used in this study was Pseudomonas aeruginosa ATCC 10145, a model organism for biofilm formation studies and a typical strain used in the evaluation of antimicrobial systems to eradicate biofilms $[23,24]$. This strain was grown at $37^{\circ} \mathrm{C}$ in Tryptone soya broth (TSB, Oxoid, Basingstoke, UK), and its dilutions were plated in Tryptone soya agar (TSA, Oxoid, Basingstoke, UK). 


\subsubsection{Biofilm Growth Protocol}

Stainless-steel disks were sterilized in an autoclave a $121^{\circ} \mathrm{C}$ for $20 \mathrm{~min}$. P. aeruginosa was cultured overnight in TSB under aerobic conditions at $37^{\circ} \mathrm{C}$. The optical density of the solution was regulated at 0.2 at $650 \mathrm{~nm}$ of wavelength, corresponding to $1 \times 10^{8}$ Colony Forming Unit (CFU) $\mathrm{mL}^{-1}$. Then the standardized suspension was diluted 1:10 with fresh TSB. The suspension was incubated at $37^{\circ} \mathrm{C}$ for $3 \mathrm{~h}$ in order to achieve the logarithmic growth phase. At the end of the time, the suspension was stored in a sterile flask containing a stainless-steel surface (diameter $2.05 \mathrm{~cm}$ ) and covered with a previously sterilized cotton plunger. Then, the flasks were incubated under aerobic conditions at $37^{\circ} \mathrm{C}$ for $48 \mathrm{~h}$ in order to promote biofilm formation $[25,26]$.

At the end of the fixed time, the stainless-steel surface was removed and transferred into a falcon tube $(50 \mathrm{~mL})$ in which there was $10 \mathrm{~mL}$ of sterile water. The falcon was shaken for $10 \mathrm{~min}$ at $100 \mathrm{rpm}$.

Then, the stainless-steel surface was washed with $10 \mathrm{~mL}$ of sterile water. Subsequently, the stainless-steel surface was carefully scraped with a bistoury to remove attached cells and washed again. Thus, the cleaning water was diluted and plated. The stainless-steel surface was transferred into a new falcon with $10 \mathrm{~mL}$ of sterile water and sonicated in a $35 \mathrm{kHz}$ ultrasonic bath (Model AL-6 Italy, Falc Instruments, Bergamo, Italy). After $5 \mathrm{~min}$, the obtained suspension was diluted and plated. All culture plates were incubated under aerobic conditions at $37^{\circ} \mathrm{C}$ for $24 \mathrm{~h}$.

Finally, the microbial count was performed, measuring the number of Colony Forming Units $\mathrm{mL}^{-1}[17,27]$. The results are expressed as percentage of the total amount of bacteria detached.

\subsubsection{Prevention of Biofilm Formation Assay}

A suspension of P. aeruginosa was prepared overnight and standardized in order to have a concentration of $1 \times 10^{8} \mathrm{CFU} \cdot \mathrm{mL}^{-1}$; four dilutions (1:10) in fresh TSB were prepared from this suspension, in order to obtain $10 \mathrm{ml}$ of bacterial suspension for each and incubated for three hours.

Then, the bacterial suspensions were placed inside four flasks with a stainless-steel disc inside. After $24 \mathrm{~h}$ of incubation at $37^{\circ} \mathrm{C}$, different weights of NAC and NACESOL ${ }^{\mathrm{TM}}$ were put in $1 \mathrm{~mL}$ of TSB in order to dissolve the active and to have different concentrations of $\mathrm{N}$-acetylcysteine $\left(0.5 \mathrm{mg} \cdot \mathrm{mL}^{-1}\right.$, $2 \mathrm{mg} \cdot \mathrm{mL}^{-1}, 4 \mathrm{mg} \cdot \mathrm{mL}^{-1}$ ) considering the final volume of $10 \mathrm{~mL}$ into the flasks. The prepared solutions were put into the flasks. The test performed using NACESOL ${ }^{\mathrm{TM}}$ takes into account the NAC concentration inside the supramolecular complex (10\%).

A bacterial suspension without any active was used as a control.

Moreover, to evaluate the contribute of NACESOL ${ }^{\mathrm{TM}}$ compounds on the biofilm reduction, tests in triplicate were performed using resveratrol, $\alpha$-cyclodextrins, and a complex of resveratrol-cyclodextrins.

After $24 \mathrm{~h}$, the suspension was removed from the incubator. The stainless-steel discs were removed and placed in $10 \mathrm{~mL}$ of sterile water and then agitated for $10 \mathrm{~min}$ at $100 \mathrm{rpm}$. The disks were then washed with $10 \mathrm{~mL}$ of sterile water and placed in another $10 \mathrm{~mL}$ of sterile water, were they were scraped with a scalpel to mechanically detach the remaining adherent cells and then sonicated for five minutes in a $35 \mathrm{kHz}$ ultrasonic bath. The suspension was diluted $(1: 100,1: 10,000 ; 1: 1,000,000)$ and plated in TSA in order to count the viable cells.

Biofilm density was calculated as percentages of its control, as reported in the literature [28], and the activity of compounds was calculated from the reduction of bacterial cells recovered at the end of the experiment, as described by the following formula:

$$
100-\frac{(\text { CFUc }- \text { CFUs })}{C F U c} * 100=\text { Bacterial Cells Reduction } \%
$$

where $C F U c$ are the colony-forming units resulting from the sum of the colonies after manual scraping and sonication of the control disk and CFUs are the colony-forming units resulting from the sum of the colonies after manual scraping and sonication of the disk treated with the active. 


\subsection{Statistical Analysis}

Experiments were performed in duplicate for three independent experiments. Statistical analysis of the data was performed for the biofilm growth protocol and by comparing the results obtained in the prevention of biofilm with different weights of NAC and NACESOL ${ }^{\text {TM }}$. It was realized by means of analysis of variance one-way (post hoc test) values transformed into logarithms (natural log).

The analyses were conducted using Prism 3.0. (GraphPad Software Inc., San Diego, CA, USA) The significance level was $p<0.05$.

\subsection{Scanning Electron Microscopy (SEM)}

Microstructural characterization of the biofilm grown on the disks before and after active treatment was performed with a high-resolution scanning electron microscope (TESCAN, Mira 3 XMU, Brno, Czech Republic). The samples were fixed, overnight in $\mathrm{OsO}_{4}$ vapour in petri dishes containing $\mathrm{OsO}_{4}$ crystals (Sigma-Aldrich, Italy). Then, all disks were air dried for one day [29]. Finally, the disks were directly mounted on aluminum pin stubs by means of a graphite tape and coated with carbon using a Cressington 208C (Cressington Scientific Instrument Ltd., Watford, UK) prior to observation.

Scanning electron microscopy (SEM) analysis was performed operating at $20 \mathrm{kV}$. Comparison of biofilms with different thicknesses was made using both Scattered Electrons (SE) and Back-Scattered Electrons (BSE) detectors. Semiquantitative composition microanalysis was determined by energy dispersive spectrometry (EDS, EDAX Ametek GmbH, Meerbusch, Germany).

\section{Results}

\subsection{Analytical Quantification of N-Acetylcysteine within NACESOL ${ }^{T M}$}

The chromatographic parameters set up in this work resulted in a calibration curve for $\mathrm{N}$-Acetylcysteine quantification with strong correlation $\left(R^{2}=0.9992\right)$ in a concentration range between $0.02-0.8 \mathrm{mg} \cdot \mathrm{mL}^{-1}$.

The method was successfully employed for the determination of $\mathrm{N}$-acetylcysteine in the NACESOL ${ }^{\mathrm{TM}}$ multi-composite. Results showed the presence of $10 \% w / w$ of NAC in the multi-composite compound.

\subsection{Chemico-Physical Characterization}

\subsubsection{DSC Measurements}

DSC measurements of NAC shows an endothermic peak (enthalpy change, $\Delta \mathrm{H} 153.4 \pm 0.4 \mathrm{~J} \cdot \mathrm{g}^{-1}$ ) at $109.2 \pm 0.1{ }^{\circ} \mathrm{C}$, attributable to the melting of the compound (Figure 1). 


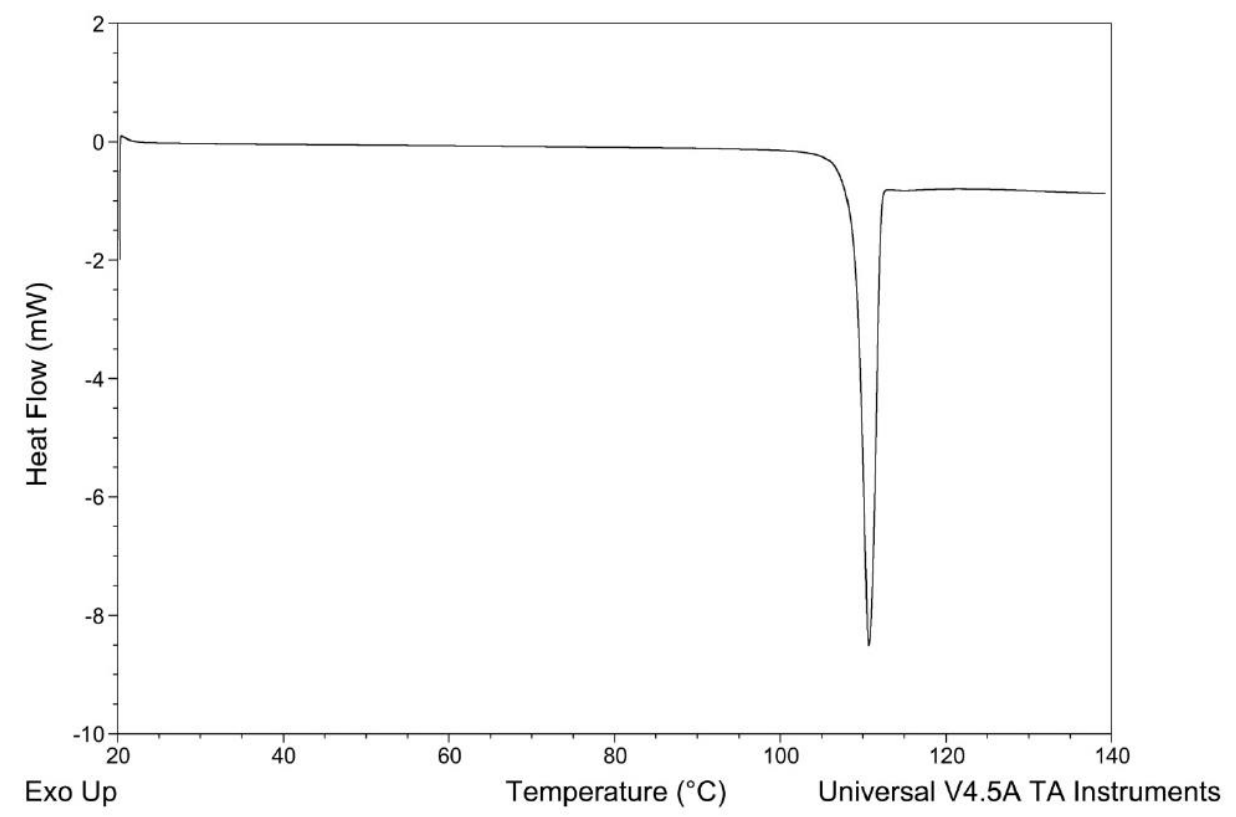

Figure 1. Differential scanning calorimetry (DSC) profile of pure N-acetylcysteine (NAC).

DSC profiles both of physical mixture NAC:resveratrol:cyclodextrin (10:15:75 w:w, MF) and of NACESOL ${ }^{\mathrm{TM}}$ show the same behavior with three different endothermic effects (Figure 2). The first one, with a $\mathrm{T}_{\text {onset }} 106.9^{\circ} \mathrm{C}$, could be due to the melting of NAC. The $\Delta \mathrm{H}$ of this peak in the physical mixture is about $15.0 \mathrm{~J} \cdot \mathrm{g}^{-1}$ and corresponds to the value that the compound should have $\left(15.3 \mathrm{~J} \cdot \mathrm{g}^{-1}\right)$ if no interaction among the components occurs in the physical mixture. The integration of this peak, due to the lack of a return of the curve to the baseline, can only be approximate. The other two unresolved peaks in the thermal range $120-230^{\circ} \mathrm{C}$ followed by an endothermic drift can be attributed to the interaction between cyclodextrin and resveratrol.

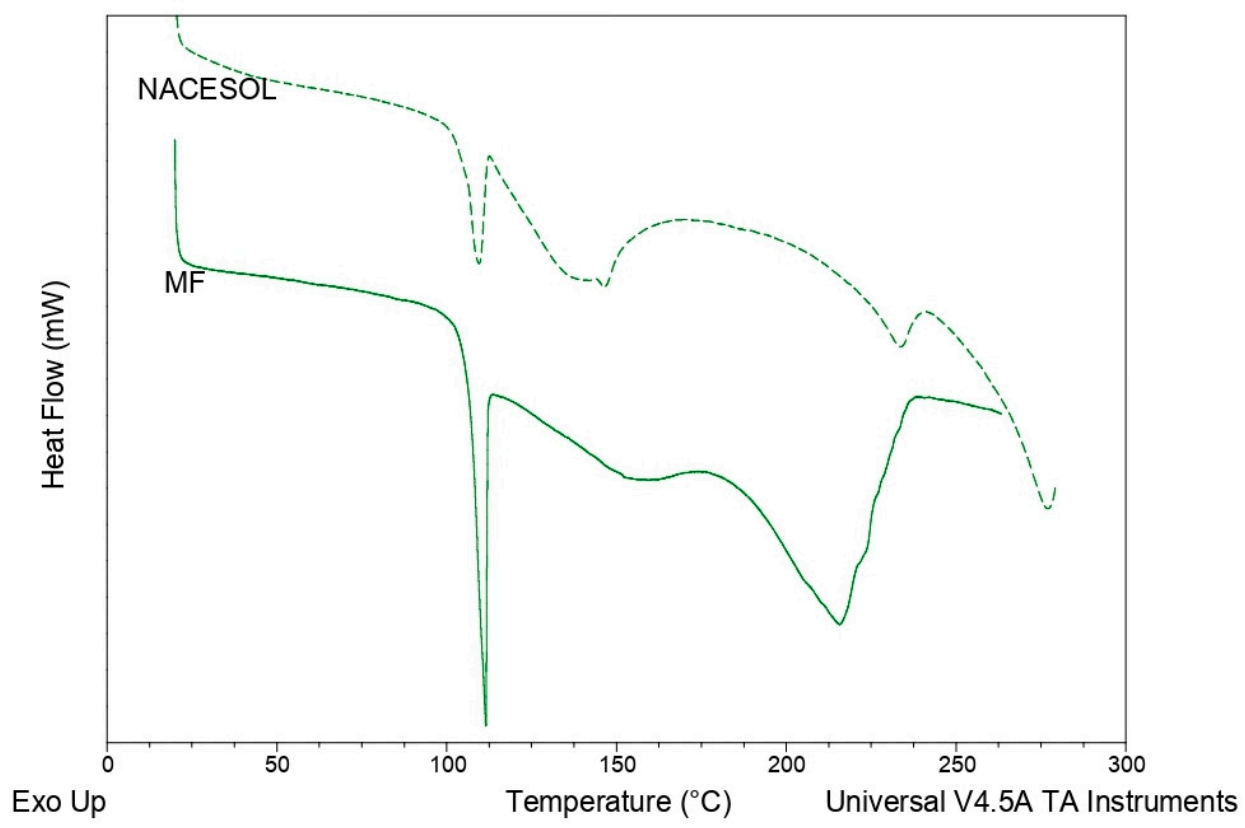

Figure 2. DSC profiles of NACESOL ${ }^{\mathrm{TM}}$ and physical mixture (MF) NAC:Resveratrol:cyclodextrin $(10: 15: 75 \mathrm{w}: \mathrm{w}: \mathrm{w})$. 
In fact, the analysis of pure resveratrol powder highlights the DSC profile with a melting point at $263.0^{\circ} \mathrm{C}$ with a $\Delta \mathrm{H}$ of $261.4 \mathrm{~J} \cdot \mathrm{g}^{-1}$, while cyclodextrin treated with patented technology shows an enlarged and asymmetric endothermic peak with $\mathrm{T}_{\text {onset }}$ of $127.4^{\circ} \mathrm{C}$ and $\Delta \mathrm{H}$ equal to $158.7 \mathrm{~J} \cdot \mathrm{g}^{-1}$ (data not reported). The absence of the resveratrol melting peak suggests that in the physical mixture, Resveratrol is present in an amorphous form, probably included in a multi-composite with cyclodextrin.

The same behavior is present in the DSC profile of NACESOL ${ }^{\mathrm{TM}}$, in which three unresolved endothermic effects occur. The peak attributable to the NAC fusion is clearly distinguished, with $\mathrm{T}_{\text {onset }}$ of $105.2^{\circ} \mathrm{C}$ and $\Delta \mathrm{H}$ of $7.3 \mathrm{~J} \cdot \mathrm{g}^{-1}$.

This value of $\Delta \mathrm{H}$ is definitely lower than the value measured in the physical mixture but still represents around $49 \%$. The thermal data therefore suggests that, in NACESOL ${ }^{\mathrm{TM}}$, a substantial percentage of NAC (about half of the quantity envisaged by the composition) is still present in crystalline form and therefore not included in multi-composite compound.

\subsubsection{XRPD Measurements}

The XRPD patterns collected on the samples are presented in Figure 3. NAC and resveratrol show typical diffraction effects of crystalline powders. In the pattern of cyclodextrin treated with the patented technology sample (blank), a hump typical of amorphous powders is evident.

In the pattern of the physical mixture sample (MF) on the hump typical of amorphous powders, the peaks of the two active ingredients are barely visible, in addition to two new peaks around $30^{\circ}$ 2-theta.

The XRPD pattern of the NACESOL ${ }^{\mathrm{TM}}$ sample shows the presence of an NAC peak around $27^{\circ}$ 2-theta. This peak is also present in the pure NAC pattern and in that of MF.

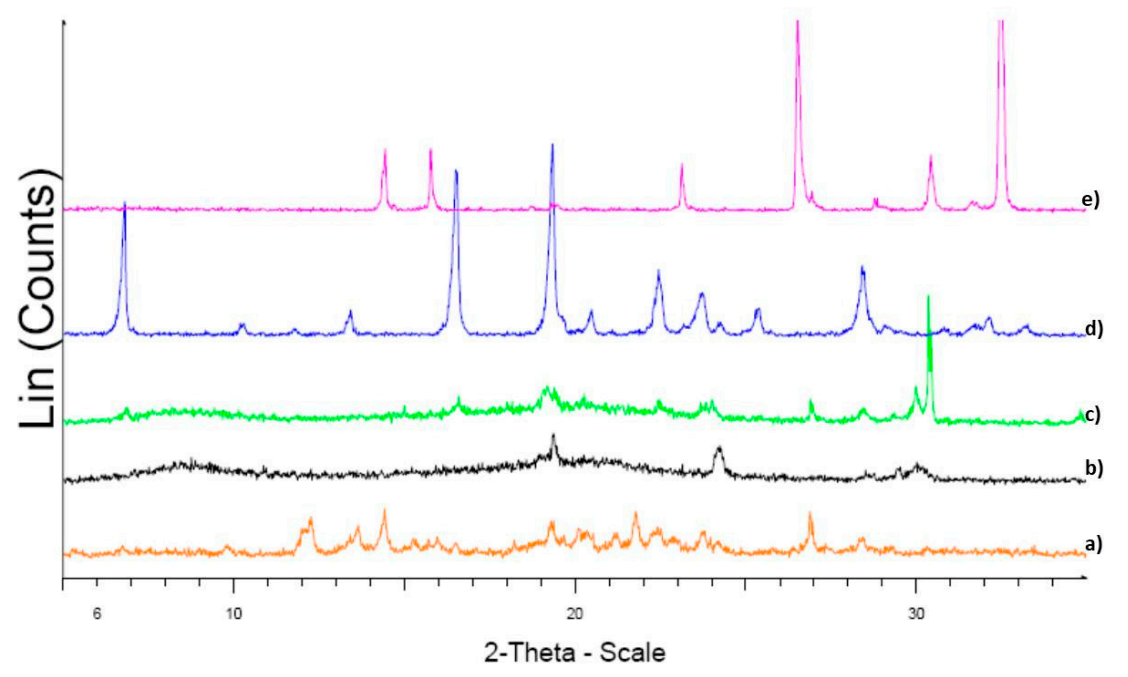

Figure 3. Pattern X-ray powder diffraction (XRPD) of (a) Nacesol ${ }^{\mathrm{TM}}$; (b) Cyclodextrin; (c) physical mixture (MF) NAC: Resveratrol: cyclodextrin (10:15:75 w:w:w); (d) Resveratrol; (e) NAC.

\subsubsection{FT-IR Measurements}

Figure 4 shows the FT-IR spectra of NAC, NACESOL ${ }^{\mathrm{TM}}$, and Resveratrol treated with Cyclodextrin in a wavenumber range of $4000-400 \mathrm{~cm}^{-1}$. 


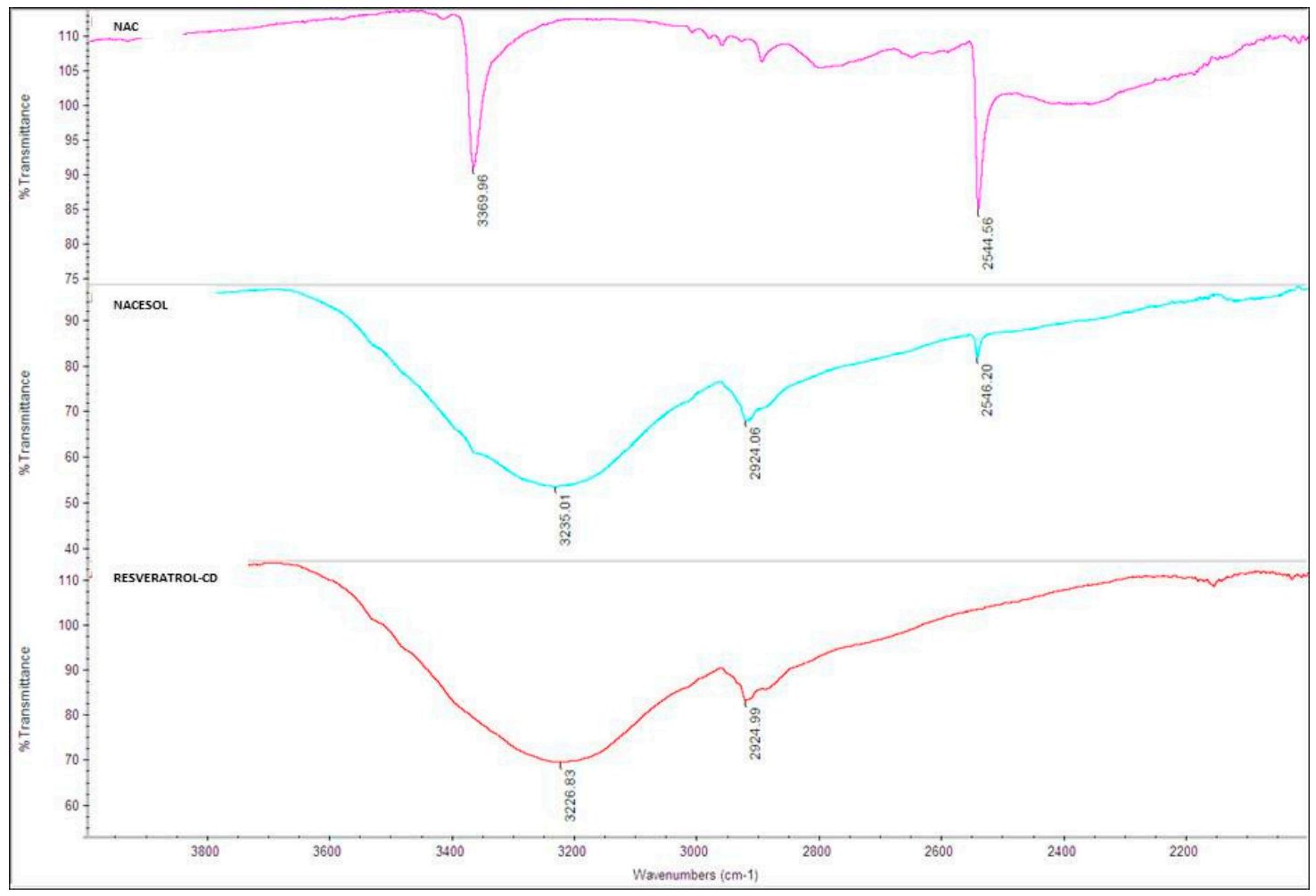

(a)

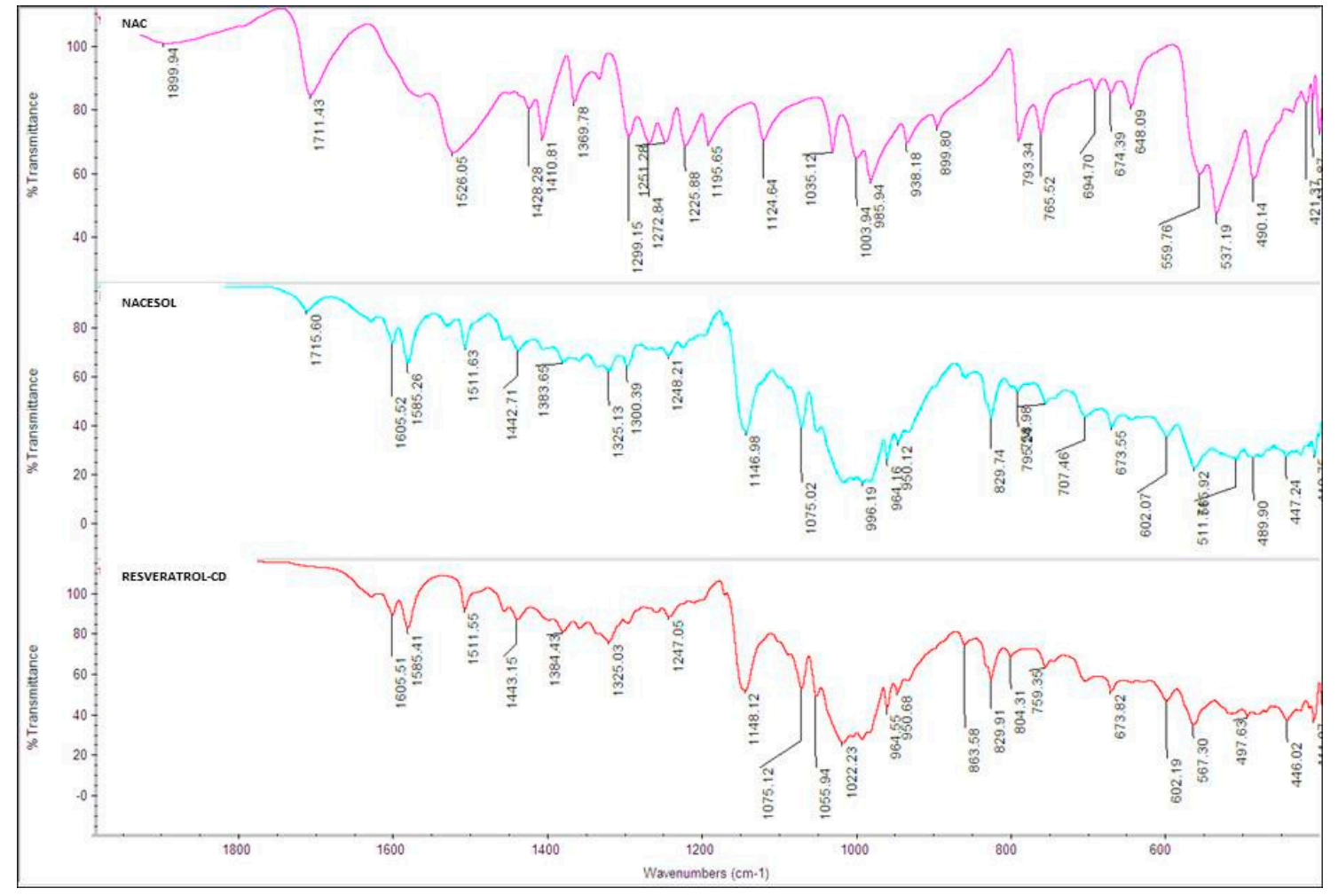

(b)

Figure 4. Fourier-transform infrared (FT-IR) spectra of NAC, NACESOL ${ }^{\mathrm{TM}}$ e Resveratrol treated with Cyclodextrin in a wavenumber range: (a) $4000-2000 \mathrm{~cm}^{-1}$; (b) $2000-400 \mathrm{~cm}^{-1}$. 
The spectrum of the NACESOL ${ }^{\mathrm{TM}}$ sample is similar to that of the resveratrol treated with cyclodextrin sample, without the NAC peaks at $2546 \mathrm{~cm}^{-1}$, due to SH stretching, $1715 \mathrm{~cm}^{-1}$, due to the stretching of the $\mathrm{C}=\mathrm{O}$ carboxylic, at $1534 \mathrm{~cm}^{-1}$ of amide II (bending $\mathrm{NH}$ ), and at $1300 \mathrm{~cm}^{-1}$.

The peak at $1534 \mathrm{~cm}^{-1}$ is shifted with respect to the pure NAC spectrum $\left(1526 \mathrm{~cm}^{-1}\right)$, and the peak at $1715 \mathrm{~cm}^{-1}$ is shifted with respect to the spectrum of the pure active ingredient NAC $\left(1711 \mathrm{~cm}^{-1}\right)$ indicating that the carboxyl group and the amidic group are probably involved in a scheme of different hydrogen bonds in the multi-composite compound.

\subsection{Biofilm Assay}

\subsubsection{Biofilm Growth Protocol}

The protocol applied in this work, set at $48 \mathrm{~h}$ of incubation time, permitted to obtain a reproducible biofilm growth on the surface of the disk, as shown in the Figure 5.

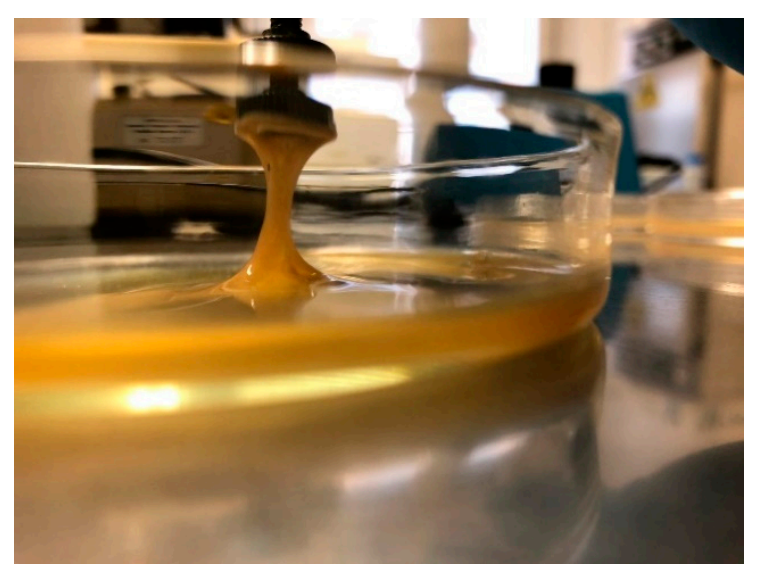

Figure 5. Biofilm appearance after $48 \mathrm{~h}$ of incubation.

The CFU number differs significantly in the three steps of biofilm removal $(p=0.002)$.

Manual scraping causes the removal of a large quantity of cells that have not been detached either from the first shaking or from the first washing ( $54.31 \%$ of the total bacteria). The second wash shows a markedly lower number of CFU, which is $0.11 \%$, showing that the planktonic cells were few because the rinsing force is not such as to detach biofilm cells. Finally, after sonication, the CFU increase exponentially, where the remaining $45.85 \%$ of the bacteria detached, demonstrating the presence of a biofilm on the surface of the disk, which is only eradicable with sonication.

\subsubsection{Biofilm Formation Assay}

Figure $6 a, b$ shows the effectiveness of free NAC and NACESOL ${ }^{\text {TM }}$ in the reduction of bacterial colonies growth, respectively. Results are expressed as percentage of bacterial cells reduction using a non-treated metal disk as a control. 


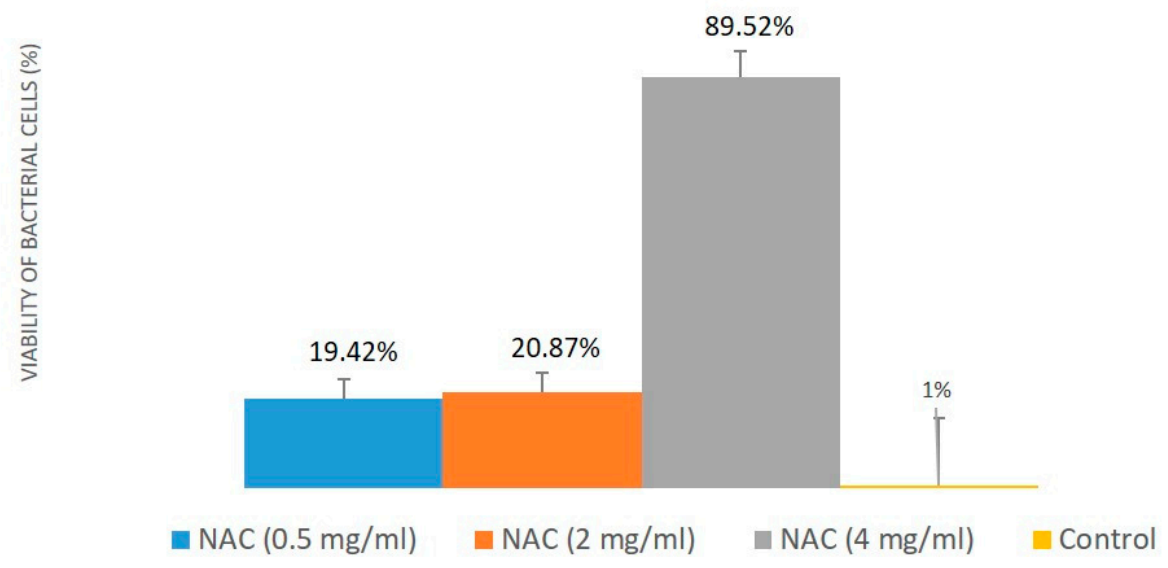

(a)

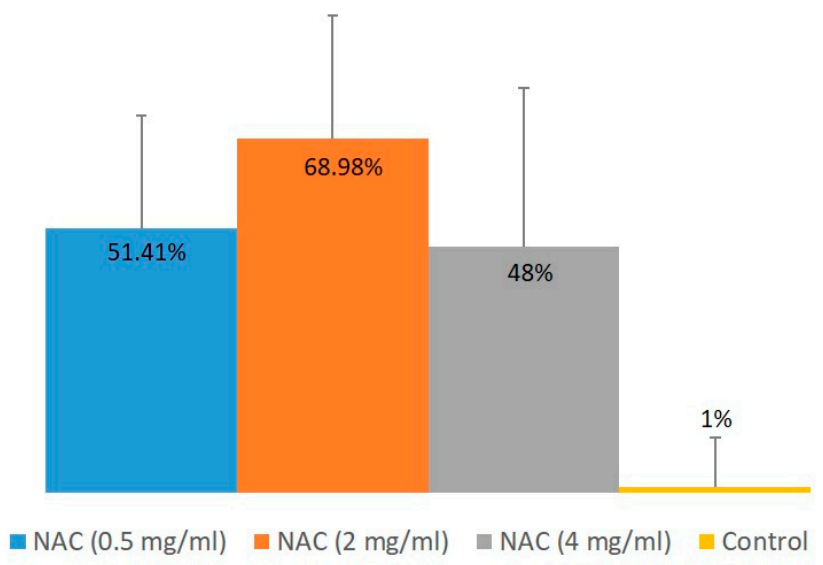

(b)

Figure 6. Percentage of biofilm reduction, expressed as a means \pm SDs, of (a) free $\mathrm{N}$-acetylcysteine, at $0.5,2,4 \mathrm{mg} \cdot \mathrm{mL}^{-1}$; control; (b) NACESOL ${ }^{\mathrm{TM}}$, at $0.5,2$, and $4 \mathrm{mg} \cdot \mathrm{mL}^{-1}$ of active; control.

In both cases, the active concentrations chosen for the test were $0.5 \mathrm{mg} \cdot \mathrm{mL}^{-1} ; 2 \mathrm{mg} \cdot \mathrm{mL}^{-1}$; $4 \mathrm{mg} \cdot \mathrm{mL}^{-1}$. These concentrations were chosen based on the literature [17]. Olofosson et al. evaluated NAC activity against a wide range of strains and discovered that NAC at the concentration of $0.5 \mathrm{mg} \cdot \mathrm{mL}^{-1}$ was able to reduce the adhesion of bacteria to steel surfaces.

The number of CFU on controls was always homogeneous for each experiment: $2.4 \times 10^{6} \pm 3.6$ $\times 10^{5}$ (Figure 6a) and $2.6 \times 10^{6} \pm 2.5 \times 10^{5}$ (Figure 6b). The control bacterial cells reduction in the NAC experiments was $1 \% \pm 14.7 \%$, and in the NACESOL ${ }^{\mathrm{TM}}$ experiments $1 \% \pm 9.6 \%$. Thus, it can be concluded that experiments are well carried out, and active results can be compared among them.

NAC is able to determine a statistically significant reduction of the number of colonies only at concentration of $4 \mathrm{mg} \cdot \mathrm{mL}^{-1}(p=0.0001)$. The results highlighted in Figure 6a show that at $0.5 \mathrm{mg} \cdot \mathrm{mL}^{-1}$ the free NAC reduces the number of colonies by $19.42 \% \pm 4.28 \%$, at $2 \mathrm{mg} \cdot \mathrm{mL}^{-1}$ the reduction is $20.87 \% \pm 4.34 \%$ while the concentration of $4 \mathrm{mg} \cdot \mathrm{mL}^{-1}$ produces a reduction of the biofilm equal to $89.52 \% \pm 5.83 \%$.

NACESOL ${ }^{\mathrm{TM}}$ shows an increase effect to compare with free NAC. In fact, the multi-composite at $0.5 \mathrm{mg} \cdot \mathrm{mL}^{-1}$ (active concentration) is able to reduce the number of colonies by $51.41 \% \pm 22.10 \%$, at $2 \mathrm{mg} \cdot \mathrm{mL}^{-1}$ the reduction is equal to $68.98 \% \pm 24.30 \%$; both reductions are statistically significant 
$(p=0.0168)$. The concentration of $4 \mathrm{mg} \cdot \mathrm{mL}^{-1}$ is not able to determine a significantly reduction $(p=$ 0.587 ) of colonies, also if results seem very good with a percentage of reduction of $48.00 \% \pm 31.14 \%$. Tests made with resveratrol, $\alpha$-cyclodextrins, and the resveratrol-cyclodextrin compound demonstrate that neither one nor others have any effect on the biofilm (data not reported).

\subsection{Scanning Electron Microscope and Elementary Analysis}

Figure 7a-d shows the SEM images of the untreated biofilm and of the biofilm formed after NAC addition at the same magnification. On the right, an SE detector was used, while on the left, a BSE detector was used.

a)

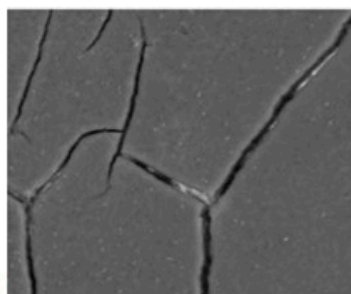

b)

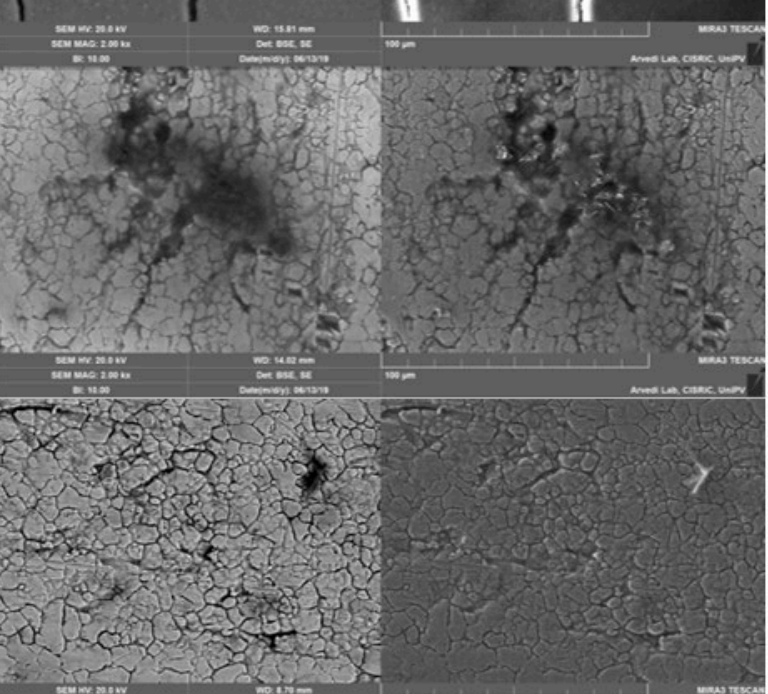

c)

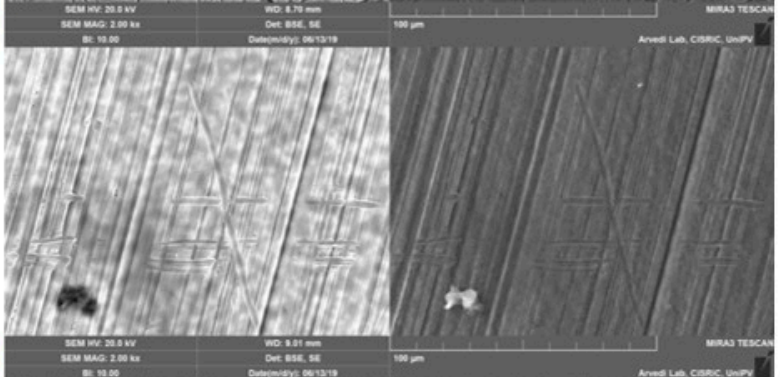

d)
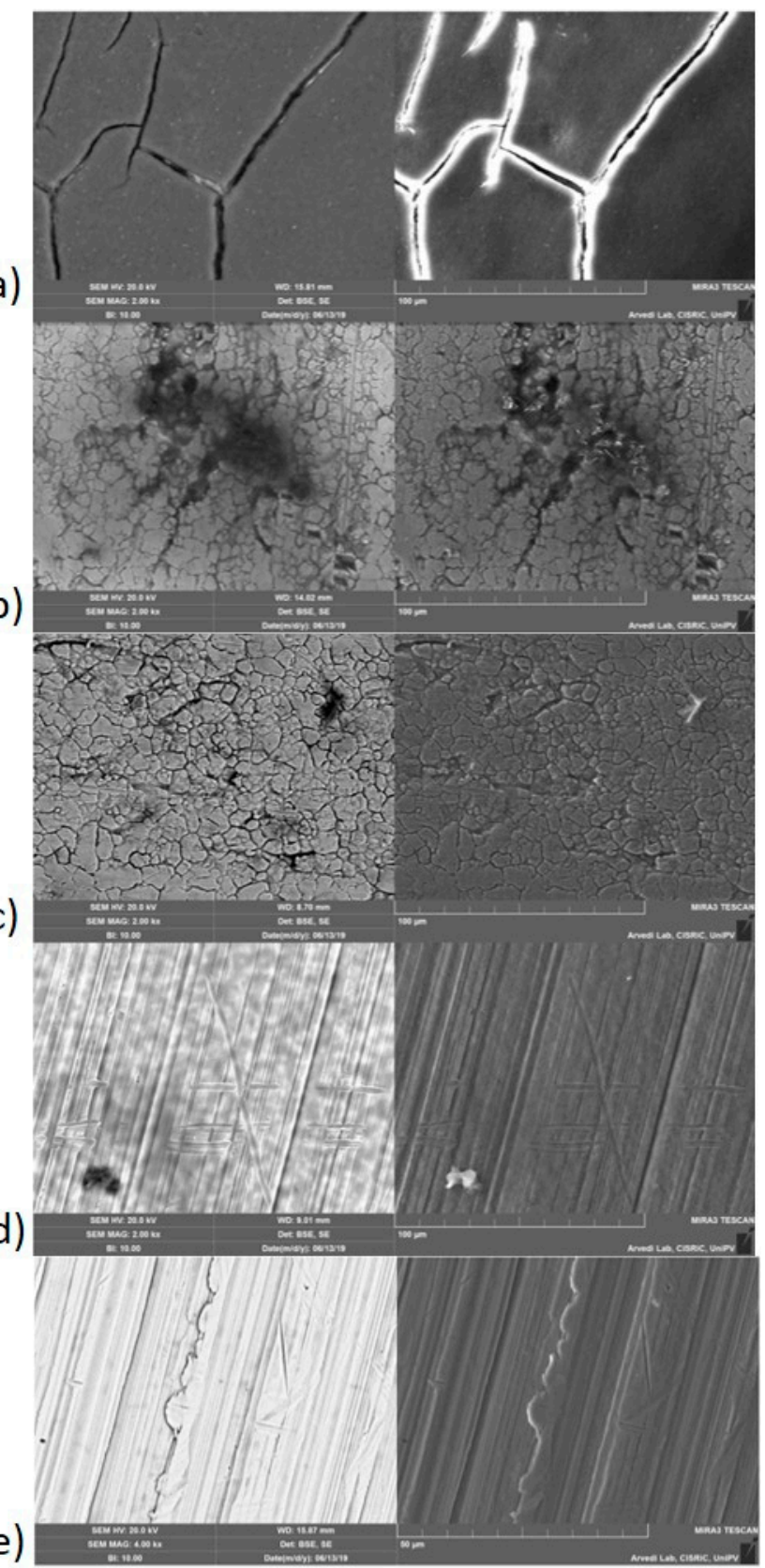

Figure 7. Scanning electron microscopy (SEM) image, using a back-scattered electrons (BSE) detector (left) or a Scattered Electrons (SE) detector (right), of: (a) untreated biofilm; (b) biofilm with $0.5 \mathrm{mg} \cdot \mathrm{mL}^{-1}$ of NAC; (c) biofilm with $2 \mathrm{mg} \cdot \mathrm{mL}^{-1}$ of NAC; (d) biofilm with $4 \mathrm{mg} \cdot \mathrm{mL}^{-1}$ of NAC; (e) clean steel-surface. 
The distinction between the biofilm presence and the clean steel can be observed as the analyses were performed using BSE detector. Figure $7 \mathrm{~b}-\mathrm{d}$ shows the biofilm with increasing NAC concentration $\left(0.5-4 \mathrm{mg} \cdot \mathrm{mL}^{-1}\right)$, together with biofilm untreated as a control (Figure $7 \mathrm{a}$ ).

As the concentration of the active increases, the biofilm decreases in thickness, until it is possible to see only the clean steel layer as in Figure $7 \mathrm{~d}$, where there is only a small organic residue.

Figure 8A-D show a higher magnification of biofilm images at different NAC concentrations.

A

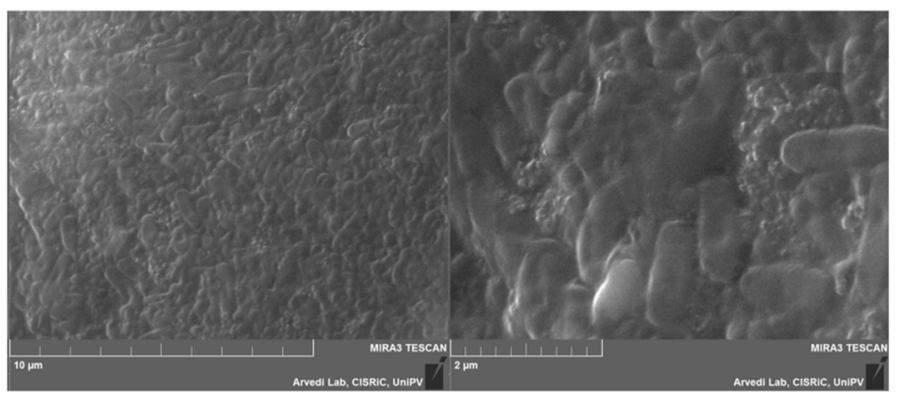

B
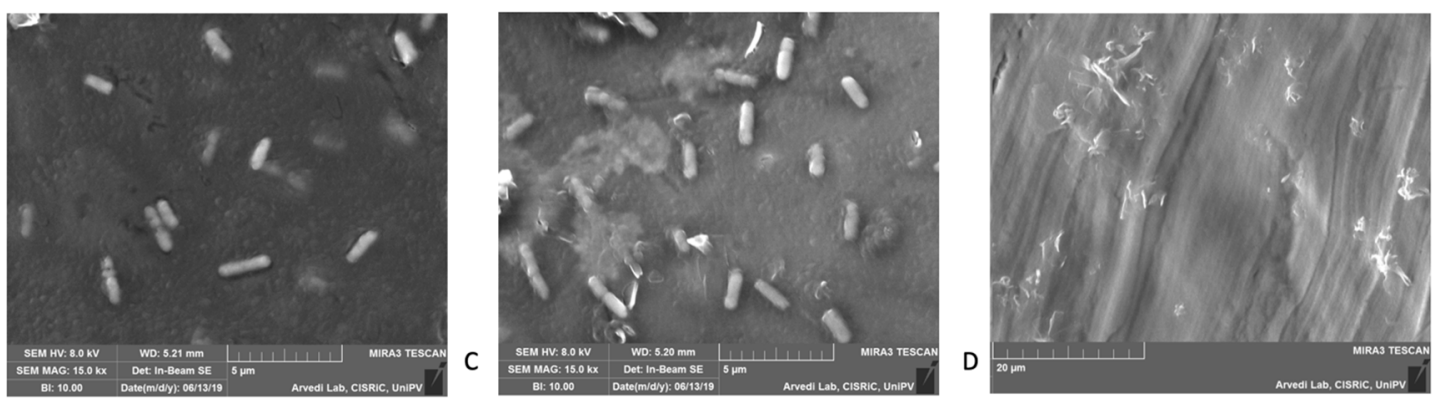

Figure 8. Higher magnification of SEM pictures of a Pseudomonas aeruginosa Biofilm on an untreated steel-surface of: (A) untreated biofilm; (B) biofilm with $0.5 \mathrm{mg} \cdot \mathrm{mL}^{-1}$ of NAC; (C) biofilm with $2 \mathrm{mg} \cdot \mathrm{mL}^{-1}$ of NAC; (D) biofilm with $4 \mathrm{mg} \cdot \mathrm{mL}^{-1}$ of NAC.

Thanks to the analysis with the SEM it was possible to verify even visually the presence of the biofilm, as clearly shown in Figure 8A-C, in which Pseudomonas aeruginosa appeared immersed in the organic matrix.

Energy Dispersive X-Ray Spectroscopy (EDS) analysis was performed to quantify the biofilm on each individual steel disk. Figure 9 and Table 1 show the plotted spectra of elements and the Sulfur atom \%, of the control disk (CTR) and of the disk with the active (ACTIVE), respectively.

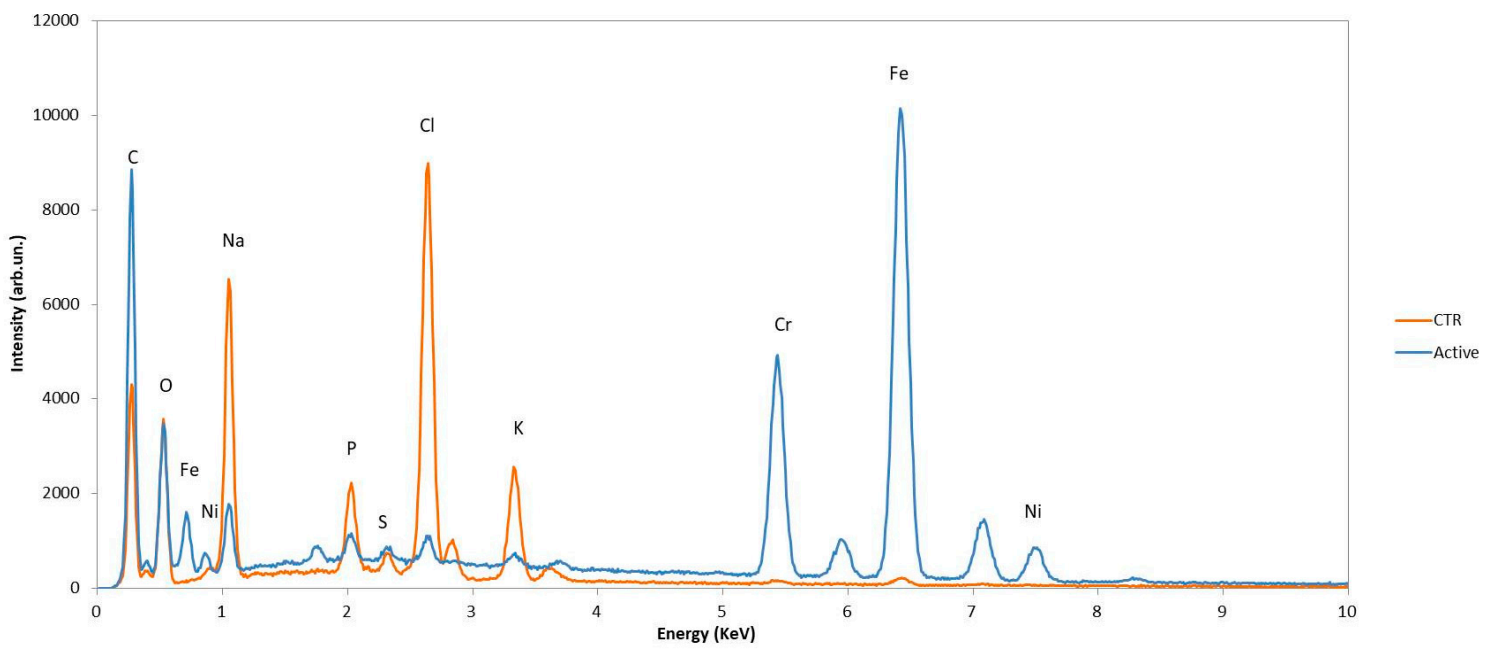

Figure 9. Plotted spectra of the control disk and the active-treated disk. 
Table 1. Atom $\%$ of sulfur on the control disk and on the disk with the active.

\begin{tabular}{ccc}
\hline & S Content (\%) & S.D. \\
\hline CTR & 0.43 & 0.018 \\
ACTIVE & 0.24 & 0.095 \\
\hline
\end{tabular}

This semiquantitative analysis allowed us to confirm that the active leads to a thinning of the biofilm.

What can be seen is that as the quantity of biofilms decreases sulfur decreases, while iron increases, demonstrating that the thickness of the biofilm decreases, while the elements of steel emerge. On the contrary, when the biofilm is thick enough, such as in the control, the elements of the steel decrease because they are hidden by the thick organic film. However, the iron value has a limited meaning in this instance, as a small amount of iron is released when cells die.

The high standard deviation (Table 1) is due to the inhomogeneity of the samples treated with the active, as the surface does not have a homogeneous layer of biofilm, as shown in Figure $7 \mathrm{~b}-\mathrm{d}$. While the standard deviation in the control appears smaller because in this case a thick and equal film has been obtained across the full surface.

\section{Discussion}

Bacterial biofilms play an important role in different types of infections, including chronic lung infections, and it represent a serious public health problem. Thus, it is necessary to study targeted antibacterial therapies in synergism with antibiotics to counteract the resistance drug of this bacterium [30]. For these reasons, NAC and NACESOL ${ }^{\mathrm{TM}}$ can play an important role.

The aim of the biofilm prevention assay was to separate planktonic cells from sessile cells, trapped in the exopolysaccharide matrix; therefore, this approach allows a concrete assessment of the presence of a biofilm and the effectiveness of active compounds in contrasting it. All the samples were treated according to an identical standardized protocol. The first washes are carried out in order to detach the planktonic cells, then the scraping has the role to detach the cell more adhered to the surface, and, at the end, the sonication was adopted to remove all the cells on the surface. Each step was made by transferring the surface in sterile water, so that the cells resulting from each step could be counted. The validity of this protocol was also confirmed by the homogeneity of the control colonies, that are the colonies deriving from the biofilm not treated with NAC $\left(2.4 \times 10^{6} \pm 3.6 \times 10^{5}\right.$ for NAC experiments, and $2.6 \times 10^{6} \pm 2.5 \times 10^{5}$ for NACESOL ${ }^{\mathrm{TM}}$ experiments).

$\mathrm{N}$-Acetyl-L-cysteine, in a free form or in a multi-composite, was inserted into the cell culture after $24 \mathrm{~h}$, not when the biofilm was fully formed, but during its formation. This protocol, applied to evaluate a preventive activity of NAC, involves the use of stressed condition of the environment in which the active must exert its activity. The number of bacterial cells detected was used as an indicator to evaluate the reduction of the biofilm.

Evaluation of free NAC against $P$. aeruginosa biofilm led to results showing its progressive reduction with the highest value $\left(89.52 \%\right.$ ) at a concentration of $4 \mathrm{mg} \cdot \mathrm{mL}^{-1}$. At 0.5 and $2 \mathrm{mg} \cdot \mathrm{mL}^{-1}$ the action of the free NAC can be compared $(19.42 \% \pm 4.28 \%$ and $20.87 \% \pm 4.34 \%)$, while it significantly increases to $4 \mathrm{mg} \cdot \mathrm{mL}^{-1}$. As observed in literature P. aeruginosa biofilms showed significant structural differences in the presence of the NAC regimen. The biomass, substratum coverage, average thickness, maximum thickness, and surface area of the biomass all decreased for biofilms grown in the presence of NAC $[16,17]$.

The introduction of the new multi-composite NACESOL ${ }^{\mathrm{TM}}$ derives from the problems related to free NAC molecule-its low bioavailability (below 5\%), due to its N-deacetylation in the intestinal mucosa and first pass metabolism in the liver, its affinity to oxidation, and its acidity $(\mathrm{pH}=2.2)$ when inhaled, which could produce caught and bronchospasm. 
The choice to use a compound such as NACESOL ${ }^{\mathrm{TM}}$, and thus the use of $\alpha$-Cyclodextrin $(\alpha-\mathrm{CD})$, is because it has several advantages over the problems of the NAC:

- Stabilization to oxidation;

- Protection against degradation of substances or by microorganisms;

- Masking of the smell;

- Catalytic activity of CDs with guest molecule.

The active molecule was inserted into the host creating the multi-composite (MComp), characterized by a rapid onset of action and a powerful release effect with additional functions that improve the characteristics of the NAC. The advantages are due to the molecular separation as the individual molecules, and not crystals, are released. Furthermore, there is a vector effect caused by the weak bonds between guest and host [31].

Components for each MComp are based on the properties of the bioactive and on the desired target; thus, each MComp is specifically designed to optimize the performance of a given ingredient.

The physico-chemical properties of the bioactive-like solubility, dissolution rate, kinetics of solubility, stability, and organoleptic characteristics-are greatly improved, since the process enhances synergism among components. Therefore, the final MComp properties are superior to the simple sum of those of starting materials.

All the techniques used in this exploratory study phase indicate that regarding the complexation of NAC with cyclodextrin, the DSC measurements are the most indicative, also because they are the only ones that can provide quantitative results. They show that about $50 \%$ of NAC is still present in crystalline form.

The advantages of this new technology are shown in the Figure $6 \mathrm{~b}$, with the evaluation of the anti-biofilm effect of the MComp based on the ternary complex NAC/ $\alpha-C D /$ resveratrol $(w / w: 10 / 75 / 15)$. Compared with the free NAC molecules the prevention activity of NACESOL ${ }^{\mathrm{TM}}$ at low concentrations is higher at $0.5 \mathrm{mg} \cdot \mathrm{mL}^{-1}$ and $2 \mathrm{mg} \cdot \mathrm{mL}^{-1}$, while at $4 \mathrm{mg} \cdot \mathrm{mL}^{-1}$ the activity seems to decrease. The loss in activity, at $4 \mathrm{mg} \cdot \mathrm{mL}^{-1}$ of NAC into the multi-composite, may be due to the concentration of cyclodextrins and resveratrol being much higher; reaching saturation point, the active is no longer able to be released in the medium.

Resveratrol and cyclodextrins are important components in the formulation of NACESOL ${ }^{\mathrm{TM}}$ even if they do not have antimicrobial activity (tests made with resveratrol, $\alpha$-cyclodextrins, and the resveratrol-cyclodextrin compound demonstrated that neither one nor others have any effect on the biofilm). In fact, biofilm is a defensive barrier against dehydration and keeps bacteria in a humid environment [32]; for this reason, resveratrol and cyclodextrins protecting against oxidation, probably make the NAC more active against biofilm.

SEM analysis has been used to confirm numerical results. The distinction between the biofilm presence and the clean steel can be observed as the analyses were performed using BSE detector. While SE detectors mainly give a topographic analysis of the surface, with contrast depending most on relief. Using a BSE detector, it is possible to enhance different amounts of the biofilm. This detector provides images with brightness depending on the elements weight, thus the metal substrate image is brighter, while the organic biofilm material is darker. In this way, when the biofilm is thinner, the brighter underlying surface made of metal is highlighted by BSE detector, showing only a thin trace of organic dark material.

Figure $7 \mathrm{~b}-\mathrm{d}$ shows the biofilm with increasing NAC concentration $\left(0.5-4 \mathrm{mg} \cdot \mathrm{mL}^{-1}\right)$, while Figure 7a shows a biofilm untreated SEM image. By increasing the concentration of the active, the biofilm thins more and more, until it is possible to see only the clean steel layer as in Figure 7e, where there is only a small organic residue. 
With EDS analysis, the presence of sulfur has been specifically researched because the disulfide bridges are the target of NAC and therefore the quantity of sulfur is directly proportional to the quantity of biofilm. The quantity of biofilms decreases, and elements such as carbon, oxygen, and sulfur decrease, demonstrating that the thickness of the biofilm decreases. On the contrary, when the biofilm is thick enough, such as in the control these element increase.

SEM techniques demand that the sample is dehydrated before the analysis, since water is incompatible with the vacuum used with the electron beam. Dehydration alters the biofilm morphology, and of the water in the extracellular polymeric substances, almost $95 \%$ is lost. However, SEM could be a key tool for the investigation of the physicochemical properties of the adhesion phenomena, with an important role in the identification of the microbial strains, three-dimensional structure, and biofilm thickness. SEM is able to provide an ultra-structural investigation, allowing imaging of the overall appearance and giving information on specific biofilm features [21,33].

\section{Conclusions}

This work aimed to evaluate the activity of a new multi-composite NACESOL ${ }^{\mathrm{TM}}$ against P. aeruginosa biofilm formation using SEM as a microbiological experiment support. SEM required the dehydration of the biofilm, and thus a matrix alteration. However, this tool is very important for preliminary analyses to understand adhesion phenomena; through the high resolution of SEM, it was possible to have a clear view of the bacteria inside the biofilm, its thickness, its morphology, and its gradual disappearance with the increase in the concentration of active. The addition of the EDS analysis, by monitoring the changes in sulfur concentration, allowed us to have a clear picture of the progressive decrease of biofilm thickness. These results were confirmed by the microbiological tests. The new multi-composite NACESOL ${ }^{\mathrm{TM}}$ described in this work, at low concentrations, showed an increase activity compared to NAC free form.

This work represents a starting point for the evaluation of the activity and the possible therapeutic application of the multi-composite NACESOL ${ }^{\mathrm{TM}}$. Moreover, the protocol adopted in this research is useful to demonstrate the ability of NAC and NACESOL ${ }^{\mathrm{TM}}$ in the prevention and reduction of a P. aeruginosa biofilm. With appropriate modifications, it could be applied to verify the eradication of a fully formed bacterial biofilm and to determine which concentrations of active compounds can be used.

Author Contributions: Conceptualization, P.P. and P.G.; Methodology, P.G., M.G., and P.P.; Investigation, M.G.; Data curation, P.P. and P.G.; First draft preparation, M.G.; Writing-review and editing, M.G., P.P., and P.G.; Supervision, P.P.; Project administration, P.P. All authors have read and agreed to the published version of the manuscript.

Funding: This research received no external funding.

Acknowledgments: The authors would thank Arvedi Laboratory, CISRiC (Centro Interdipartimentale di Studi e Ricerche per la Conservazione del Patrimonio Culturale), University of Pavia, Pavia, Italy, for allowing the use of their scanning electron microscope.

Conflicts of Interest: The authors declare no conflict of interest.

\section{References}

1. Hentzer, M.; Teitzel, G.M.; Balzer, G.J.; Heydorn, A.; Molin, S.; Givskov, M.; Parsek, M.R. Alginate Overproduction Affects Pseudomonas aeruginosa Biofilm Structure and Function. J. Bacteriol. 2001, 183, 5395-5401. [CrossRef] [PubMed]

2. Bjarnsholt, T.; Jensen, P.Ø.; Fiandaca, M.J.; Pedersen, J.; Hansen, C.R.; Andersen, C.B.; Pressler, T.; Givskov, M.; Høiby, N. Pseudomonas aeruginosabiofilms in the respiratory tract of cystic fibrosis patients. Pediatr. Pulmonol. 2009, 44, 547-558. [CrossRef] [PubMed]

3. O’Toole, G. Biofilm formation as mi-crobial development. Annu. Rev. Microbiol. 2000, 54, 49-79. [CrossRef] [PubMed]

4. Costerton, J.W. Microbial biofilms. Annu. Rev. Microbiol. 1995, 49, 711-745. [CrossRef] 
5. Lewandowski, Z. Structure and function of biofilm. In Biofilm: Recent Advances in Their Study and Control; Harwood Academic Publishers: Amsterdam, The Netherlands, 2000; pp. 1-17.

6. Donlan, R.M. Role of Biofilms in Antimicrobial Resistance. ASAIO J. 2000, 46, S47-S52. [CrossRef] [PubMed]

7. Lam, J.; Chan, R.; Lam, K.; Costerton, J.W. Production of mucoid microcolonies by Pseudomonas aeruginosa within infected lungs in cystic fibrosis. Infect. Immun. 1980, 28, 546-556.

8. Heydon, A. Experimental reproducibility in flow-chamber biofilms. Microbiology 2000, 146, $2409-2415$. [CrossRef]

9. Pedersen, S.S.; Kharazmi, A.; Espersen, F.; Høiby, N. Pseudomonas aeruginosa alginate in cystic fibrosis sputum and the inflammatory response. Infect. Immun. 1990, 58, 3363-3368. [CrossRef]

10. Ryder, C.; Byrd, M.; Wozniak, D.J. Role of polysaccharides in Pseudomonas aeruginosa biofilm development. Curr. Opin. Microbiol. 2007, 10, 644-648. [CrossRef]

11. Nivens, D.E. Role of alginate and its $\mathrm{O}$ acetylation in formation of Pseudomonas aeruginosa mi- crocolonies and biofilms. J. Bacteriol. 2001, 183, 1047-1057. [CrossRef]

12. Ma, L.; Conover, M.; Lu, H.; Parsek, M.R.; Bayles, K.; Wozniak, D.J. Assembly and Development of the Pseudomonas aeruginosa Biofilm Matrix. PLoS Pathog. 2009, 5, e1000354. [CrossRef] [PubMed]

13. Friedman, L.; Kolter, R. Genes involved in matrix formation in Pseudomonas aeruginosa PA14 biofilms. Mol. Microbiol. 2003, 51, 675-690. [CrossRef] [PubMed]

14. Tirouvanziam, R.; Conrad, C.K.; Bottiglieri, T.; Herzenberg, L.A.; Moss, R.B.; Herzenberg, L.A. High-dose oral N-acetylcysteine, a glutathione prodrug, modulates inflammation in cystic fibrosis. Proc. Natl. Acad. Sci. USA 2006, 103, 4628-4633. [CrossRef] [PubMed]

15. Aldini, G. N-Acetylcysteine as an antioxidant and diuslphide bond breaking agent: The reasons why. Free Radic. Res. 2018, 52, 751-762. [CrossRef]

16. Zhao, T. N-acetylcysteine inhibit biofilms produced by Research article Pseudomonas aeruginosa. BMC Microbiol. 2010, 10, 140. [CrossRef]

17. Olofosson, A.C. N-Acetyl-L-Cysteine affects growth, extracellular polysaccharide production, and bacterial biofilm formation on solid surface. Appl. Environ. Microbiol. 2003, 69, 4814-4822. [CrossRef]

18. Carli, F. Co-Grinding Process for the Preparation of a Ternary Composition. Patent Number WO 03/097012 A1, 27 November 2003.

19. Samuni, Y.; Goldstein, S.; Dean, O.M.; Berk, M. The chemistry and biological activities of N-acetylcysteine. Biochim. Biophys. Acta (BBA)-Gen. Subj. 2013, 1830, 4117-4129. [CrossRef]

20. Gulcin, I. Antioxidant properties of resveratrol: A structure-activity insight. Innov. Food Sci. Emerg. Technol. 2010, 11, 210-218. [CrossRef]

21. Calheiros, L. SEM analysis of surface impact on biofilm antibiotic treatment. Scanning 2017, 2017, 2960194.

22. Archakam, S.C. Quantitative determination of N-acetylcysteine by RP-HPLC method in bulk and parenteral inijection. Asian J. Pharm. Pharmacol. 2018, 4, 702-705. [CrossRef]

23. Ceresa, C.; Fracchia, L.; Williams, M.; Banat, I.M.; De Rienzo, M.A.D. The effect of sophorolipids against microbial biofilms on medical-grade silicone. J. Biotechnol. 2019, 309, 34-43. [CrossRef] [PubMed]

24. Pires, D.P.; Cerqueira, M.A.; Faustino, A.; Azeredo, J. Use of newly isolated phages for control of Pseudomonas aeruginosa PAO1 and ATCC 10145 biofilms. Res. Microbiol. 2011, 162, 798-806. [CrossRef] [PubMed]

25. Chen, X.; Stewart, P.S. Biofilm removal caused by chemical treatments. Water Res. 2000, 34, 4229-4233. [CrossRef]

26. Taglietti, A. Antibiofilm activity pf monolayer of silver nanoparticles anchored to an amino-silanized glass surface. Biomaterial 2014, 35, 1779-1788. [CrossRef] [PubMed]

27. Bakich, S.L. Protocol for Simulated Natural Biofilm Formation. Patent Number EP1053299A1, 12 February 1999.

28. Li, X.-H.; Kim, S.-K.; Lee, J.-H. Anti-biofilm effects of anthranilate on a broad range of bacteria. Sci. Rep. 2017, 7, 8604. [CrossRef]

29. Greco, C.; Martincic, I.; Gusinjac, A.; Kaláb, M.; Yang, A.-F.; Ramírez-Arcos, S. Staphylococcus epidermidis forms biofilms under simulated platelet storage conditions. Transfusion 2007, 47, 1143-1153. [CrossRef]

30. Maurice, N.M.; Bedi, B.; Sadikot, R.T. Pseudomonas aeruginosa Biofilms: Host Response and Clinical Implications in Lung Infections. Am. J. Respir. Cell Mol. Boil. 2018, 58, 428-439. [CrossRef] 
31. Del Valle, M. Cyclodextrins and theri uses: A review. Process Biochem. 2003, 39, 1033-1046. [CrossRef]

32. La Placa, M. I Principi di Microbiologia Medica, 12th ed.; Esculapio: Bologna, Italy, 2010.

33. El Abed, S. Scanning Electron Microscopy (SEM) and enviromental SEM: Suitable tools for study of adhesion stage and biofilm formation. Scanning Electron Microsc. 2012, 35, 717-730. [CrossRef]

(C) 2020 by the authors. Licensee MDPI, Basel, Switzerland. This article is an open access article distributed under the terms and conditions of the Creative Commons Attribution (CC BY) license (http://creativecommons.org/licenses/by/4.0/). 